\title{
Avaliação da Educação Superior: limites e possibilidades do Núcleo Docente Estruturante
}

\author{
Evaluation of Higher Education: limits and possibilities of \\ the Structuring Teaching Core
}

Evaluación de la Educación Superior: límites y posibilidades del Núcleo Docente Estructurante

\section{Alboni Marisa Dudeque Pianovski Vieira, Sirley Terezinha Filipak*}

\section{Resumo}

O artigo se insere nas políticas públicas relativas à avaliação da Educação Superior e sua relação com a qualidade da gestão, em especial no que se refere ao Núcleo Docente Estruturante (NDE), implantado pela Resolução n. 1/2010 - CONAES, o qual possui atribuições acadêmicas de acompanhamento do projeto pedagógico do curso no processo de

* AMDPV: professora, doutora em Educação, e-mail: alboni.vieira@pucpr.br STF: professora, doutora em Educação, e-mail: sirley.filipak@pucpr.br 
sua concepção, consolidação e atualização. O objetivo da pesquisa é discutir a percepção dos integrantes do NDE de cursos ofertados por uma universidade privada a respeito dessa relação. Como objetivos específicos, são discutidos e analisados: a) os fundamentos políticos que culminaram com a obrigatoriedade da criação do NDE em todos os cursos de graduação; b) a percepção dos membros do NDE dos cursos pesquisados a respeito da exigência de sua implantação, da atuação do NDE do qual participa e de limites e possibilidades evidenciados; e c) a relação entre a atuação do NDE e a coordenação do curso. O estudo está fundamentado em documentos que tratam das políticas de gestão e avaliação institucional na Educação Superior no Brasil. Buscou-se apoio teórico nos trabalhos de Costa (2005), Gutierrez e Catani (2011) e Lück (2011), entre outros. De abordagem qualitativa, a análise dos dados coletados por meio de questionários subsidiou-se nas orientações de Bogdan e Biklen (1994) e André (2006). Os resultados apontaram para a relevância da atuação do NDE, como responsável pelo acompanhamento no processo de concepção, consolidação e contínua atualização do projeto pedagógico de curso, com vistas à melhoria de sua qualidade.

Palavras-chave: Núcleo Docente Estruturante. Sistema Nacional de Avaliação da Educação Superior. Gestão da Educação Superior.

\begin{abstract}
The paper addresses public policies related to the evaluation of Higher Education and their relation to management quality, in particular regarding the Structuring Teaching Core (implemented by Resolution n. 1/2010 - CONAES), which has academic assignments of monitoring the course pedagogical project in its design, consolidation and update. The research aims to discuss how courses offered by one private university are perceived by the members of their respective Structuring Teaching Cores on this relationship. As specific objectives, the following topics are discussed and analyzed: a) the political ground that culminated in the mandatory creation of Structuring Teaching Cores in all undergraduate courses, b) how the members of the surveyed courses' STCS perceive the requirement of their implementation, the performance of the corresponding STC, and the limits and possibilities evidenced, and c) the relationship between STC performance and course coordination. The study is based on documents about policies on institutional management
\end{abstract}


and assessment in Higher Education in Brazil. Theoretical support was sought in the work of Costa (2005), Gutierrez and Catani (2011), and Lück (2011), among others. The analysis of the data collected through questionnaires was approached qualitatively and followed the guidance of Bogdan and Biklen (1994) and André (2006). The results pointed to the importance of the STC role, as responsible for monitoring the process of design, consolidation and continuous update of the course pedagogical project, aiming to improve its quality.

Keywords: Structuring Teaching Core. National System of Higher Education Evaluation. Higher Education management.

\section{Resumen}

El artículo forma parte de las políticas públicas relativas a la evaluación de la Educación Superior y su relación con la calidad de la gestión, especialmente en lo que se refiere al Núcleo Docente Estructurante (NDE), implantado por la Resolución n. 1/2010 - CONAES, que tiene atribuciones académicas de seguimiento del proyecto pedagógico del curso en el proceso de su diseño, consolidación y actualización. El objetivo de la investigación es analizar la percepción de los miembros del NDE de cursos ofrecidos por una universidad privada con respecto a esta relación. Como objetivos específicos se discuten y se analizan: a) los fundamentos políticos que culminaron en la exigencia de la creación del NDE en todos los cursos de pregrado; $b$ ) la percepción de los miembros del NDE de los cursos investigados con respecto a la exigencia de su implantación, de la actuación del NDE en el que participa y de los límites y posibilidades evidenciadas; c) la relación entre la actuación del NDE y la coordinación del curso. El estudio está basado en documentos que tratan sobre las políticas de gestión y evaluación institucional en la educación superior en Brasil. Se buscó apoyo teórico en la obra de Costa (2005), Gutierrez y Catani (2011) y Lück (2011), entre otros. De enfoque cualitativo, el análisis de los datos recogidos a través de cuestionarios se sustentó en las directrices de Bogdan y Biklen (1994) y André (2006). Los resultados apuntaron a la importancia de la actuación del NDE, como responsable del seguimiento del proceso de diseño, consolidación y actualización permanente del proyecto pedagógico del curso, con el fin de mejorar su calidad.

Palabras Clave: Núcleo Docente Estructurante. Sistema Nacional de Evaluación de la Educación Superior. Gestión de la Educación Superior. 


\section{Introdução}

As políticas públicas sociais, dentre elas as políticas educacionais, não são práticas neutras, uma vez que estão enraizadas em bases epistemológicas que traduzem as concepções de homem, de mundo e de sociedade vigentes num determinado momento histórico, e que condicionam as relações estabelecidas entre o sujeito e o objeto do conhecimento. Segundo Santos (2011, p. 36), a análise dessas bases epistemológicas "supõe, e até exige, uma análise dos paradigmas que fundamentam as formas de organização social e política assumidas pela sociedade atual". As ideias e tendências que se revezam no poder, portanto, conformam as políticas sociais e, em particular, as políticas educacionais.

No Brasil, a passagem de um regime autoritário para um regime democrático trouxe a necessidade de serem adotados princípios democráticos, consignados na Constituição Federal de 1988 (BRASIL, 1988), e que repercutiram nos processos de gestão das políticas públicas educacionais de uma forma geral. Na esteira de adoção desses princípios, a Lei n. 9.394, que trata das Diretrizes e Bases da Educação Nacional (BRASIL, 1996), a Lei n. 10.861, que instituiu o Sistema Nacional de Avaliação da Educação Superior - SINAES (BRASIL, 2004) e a regulamentação suplementar que se lhes seguiu, foram, gradualmente, imprimindo uma nova direção às políticas públicas, para que se adequassem às exigências democratizantes.

Esses princípios democráticos, ao se concretizarem na gestão, que não é uma prática neutra, encontram

limites e condicionantes epistemológicos, políticos e pedagógicos, entre outras dimensões, advindos das opções dos que estão no poder e que interferem diretamente no alcance de uma educação com qualidade social, mas que igualmente podem ser recriadas no contexto da prática (SANTOS, 2011, p. 52).

Na gestão democrática da Educação Superior, avaliação e qualidade são pontos de destaque. Nesse sentido, a participação de órgãos colegiados ganhou força, possibilitando ao corpo docente das instituições 
pensar e tomar decisões em contextos histórico-sociais mais amplos. A discussão do Projeto Pedagógico de Curso e a atuação do Núcleo Docente Estruturante, realizada por órgãos colegiados, são representativas dessa participação.

Este artigo, na sequência dessa reflexão, no contexto das políticas públicas relativas à avaliação da educação superior em sua relação com a qualidade da gestão, tem como objeto o Núcleo Docente Estruturante, implantado pela Resolução n. 1 da Comissão Nacional de Avaliação da Educação Superior (CONAES, 2010b), órgão colegiado que possui atribuições acadêmicas de acompanhamento do projeto pedagógico do curso no processo de sua concepção, consolidação e atualização. Pelo fato de o Núcleo Docente Estruturante (NDE) ser um órgão recentemente criado na política avaliativa do Ministério da Educação (MEC), é oportuno investigar que percepção os integrantes do NDE dos diferentes cursos de graduação de uma instituição de Educação Superior possuem a respeito de seu papel, seus limites e suas possibilidades, bem como dos cuidados que devem tomar em sua esfera de competência.

Como objetivos específicos, são discutidos e analisados os seguintes tópicos: a) os fundamentos políticos que culminaram com a obrigatoriedade da criação dos Núcleos Docentes Estruturantes em todos os cursos de graduação; b) a percepção dos membros do NDE dos cursos pesquisados a respeito da exigência de sua implantação, da atuação do NDE do qual participa e de limites e possibilidades evidenciados; e c) a relação entre a atuação do NDE e a coordenação do curso.

O estudo está fundamentado em documentos que tratam das políticas de gestão e avaliação institucional na Educação Superior no Brasil. Buscou-se apoio teórico nos trabalhos de Costa (2005), Gutierrez e Catani (2011) e Lück (2011), entre outros.

Do ponto de vista metodológico, a pesquisa, de caráter interdisciplinar, está centrada no estudo de caso. Os dados foram coletados por meio de questionários aplicados aos integrantes do NDE dos cursos da universidade pesquisada, analisados com base nas orientações de Bogdan e Biklen (1994) e de André (2006). 
Os resultados apontaram para a relevância da atuação do NDE, como responsável pelo acompanhamento no processo de concepção, consolidação e contínua atualização do projeto pedagógico de curso, com vistas à melhoria de sua qualidade. Sinalizaram, também, sobre sua colaboração no processo de qualificação do corpo docente e de implantação de inovações metodológicas no curso.

\section{Histórico e atribuições do Núcleo Docente Estruturante}

Na esteira da democratização da gestão e do poder partilhado, o Núcleo Docente Estruturante, instituído pela Portaria do Ministério da Educação n. 147/2007, no instrumento de avaliação para autorização dos cursos de graduação em Medicina (art. $2^{\circ}$, inciso IV) e Direito (art. $3^{\circ}$, inciso II) que, à época, tramitavam no Ministério da Educação, como órgão responsável pela formulação, implementação e desenvolvimento do projeto pedagógico do curso, atendia também a uma antiga reivindicação da Comissão de Ensino Jurídico da Ordem dos Advogados do Brasil. Segundo a professora Maria Elba Dantas de Moura Pereira ${ }^{1}$, Diretora de Avaliação dos Cursos de Graduação do Instituto Nacional de Estudos e Pesquisas Educacionais Anísio Teixeira (Inep), no período 2008-2010, a experiência bem-sucedida na Universidade Federal da Paraíba (UFPB) atribuir a um grupo de professores líderes a incumbência de alavancar os cursos de graduação que apresentavam padrão de qualidade inferior

\footnotetext{
1 A professora Maria Elba Dantas de Moura Pereira, da Universidade Federal da Paraíba (UFPB), consultada a respeito da origem do NDE, uma vez que as pesquisadoras não encontraram órgão similar em instituições de Educação Superior europeia e norte-americana, em e-mail enviado em 18 de fevereiro de 2013, assim se pronunciou: "Houve, a respeito do NDE, uma experiência nossa, da UFPB, de comissões, por curso, que estavam se reunindo para elaborar, acompanhar e/ ou avaliar os PPCs. A Iguatemy [Maria de Lucena Martins, Diretora do Departamento de Avaliação do Ensino Superior do INEP no período 2008-2010] e eu vínhamos da PRG/UFPB que, na época em que ela foi pró-reitora e eu sua assessora e presidente da CPA, efervescia com as ações relativas aos PPCs e à avaliação. Então, nós relatamos as experiências dessas comissões que, depois de muita depuração, terminaram por se transformar em NDE. Foi assim".
} 
ao esperado - contribuiu para consolidar aquela exigência nos instrumentos de avaliação. Essa menção é corroborada pela CONAES, em seu Parecer n. 4 (CONAES, 2010a), ao afirmar que a ideia surgiu "da constatação de que um bom curso de graduação tem alguns membros do seu corpo docente que ajudam a construir a identidade do curso". Esses professores exercem uma liderança no curso que está além dos cargos instituídos, constituindo-se referências tanto para os alunos como para a comunidade acadêmica em geral. Contar com sua contribuição na concepção, na consolidação e na permanente atualização de um projeto pedagógico de curso traria também, como vantagem, um Projeto Pedagógico de Curso (PPC) que não fosse uma peça meramente documental, mas que envolvesse e corresponsabilizasse pessoas fortemente vinculadas ao curso. Ainda de acordo com o mencionado Parecer, pode-se dizer que esse grupo de professores constituiria a "alma do curso" ou, em outras palavras, "um núcleo docente estruturante" (CONAES, 2010a).

Acrescenta Pereira (2011, p. 39):

A concepção do Núcleo Docente Estruturante (NDE) deveu-se à constatação de que o Projeto Pedagógico de Curso deve ser objeto de criação coletiva por educadores que representem o perfil esperado do projeto a ser desenvolvido, realçando a característica pluralista na formação das atividades principais do curso.

De acordo com a Portaria Normativa MEC n. 40 (BRASIL, 2007), item 9.4 do Anexo, o NDE seria constituído por um:

[...] conjunto de professores da instituição responsável pela formulação do projeto pedagógico do curso, sua implementação e desenvolvimento, composto por professores com titulação em nível de pós-graduação stricto sensu, contratados em regime de trabalho que assegure preferencialmente dedicação plena ao curso, e com experiência docente (BRASIL, 2007).

Em 2008, o Instrumento de Avaliação de Cursos de Graduação (Bacharelado e Licenciatura) do Sistema Nacional de Avaliação da 
Educação Superior (SINAES), aprovado pela Portaria n. 1.081, de 29 de agosto de 2008, na Dimensão 2 (Corpo Docente, Discente e Técnicoadministrativo), Indicador 2.2, passou a exigir a "Caracterização (tempo de dedicação e de permanência sem interrupção), composição e titulação do Núcleo Docente Estruturante (NDE)”. No glossário que integrou a mencionada Portaria, o NDE era caracterizado como "um conjunto de professores, de elevada formação e titulação, contratados em tempo integral e parcial, que respondem mais diretamente pela criação, implantação e consolidação do Projeto Pedagógico do Curso" (BRASIL, 2008).

O NDE foi inserido também como "requisito legal", no instrumento de avaliação, por meio de uma pergunta que cabia à comissão avaliadora do Inep responder: "O curso possui NDE responsável pela formulação do projeto pedagógico do curso, sua implementação e desenvolvimento, com titulação em nível de pós-graduação stricto sensu e contrato de trabalho que assegure preferencialmente dedicação plena ao curso e experiência docente?" (BRASIL, 2008). Essa exigência foi contestada por diferentes setores da academia, dado que, embora constasse como requisito legal dos instrumentos de avaliação de cursos, não estava amparada em nenhuma norma emanada de órgão oficial competente.

A partir dessa exigência, a instituição pesquisada orientou os cursos de graduação para que fossem constituídos os respectivos Núcleos Docentes Estruturantes, com indicação de seus membros pelo colegiado do curso e comunicação dessa decisão, por ofício do coordenador, à Pró-Reitoria Acadêmica. A composição do NDE era feita por $30 \%$ dos docentes atuantes no curso, titulados em programa de pós-graduação stricto sensu e com regime de trabalho em tempo integral ou parcial. Naquele momento, não havia a possibilidade de professores especialistas integrarem o NDE, o que, mais tarde, passou a ser autorizado pela CONAES.

As divergências a respeito do aspecto legal que pairavam sobre o NDE foram, por fim, dirimidas pela Resolução n. 1, de 17 de junho de 2010, que tratou da constituição e normatização do Núcleo Docente Estruturante, considerando-o elemento diferenciador da qualidade do 
curso, quanto à interação entre o corpo docente e ao Projeto Pedagógico do Curso.

De acordo com o parágrafo único do art. $1^{\circ}$ da Resolução n. 1 (CONAES, 2010b):

O NDE deve ser constituído por membros do corpo docente do curso, que exerçam liderança acadêmica no âmbito do mesmo, percebida na produção de conhecimentos na área, no desenvolvimento do ensino, e em outras dimensões entendidas como importantes pela instituição, e que atuem sobre o desenvolvimento do curso.

No art. $2^{\circ}$, as atribuições do Núcleo Docente Estruturante estão genericamente definidas:

I - contribuir para a consolidação do perfil profissional do egresso do curso; II - zelar pela integração curricular interdisciplinar entre as diferentes atividades de ensino constantes no currículo;

III - indicar formas de incentivo ao desenvolvimento de linhas de pesquisa e extensão, oriundas de necessidades da graduação, de exigências do mercado de trabalho e afinadas com as políticas públicas relativas à área de conhecimento do curso;

IV - zelar pelo cumprimento das Diretrizes Curriculares Nacionais para os Cursos de Graduação (CONAES, 2010b).

$\mathrm{O}$ art. $3^{\circ}$ da Resolução estabelece os seguintes critérios mínimos para se constituir o NDE:

I - ser constituído por um mínimo de 5 professores pertencentes ao corpo docente do curso;

II - ter pelo menos $60 \%$ de seus membros com titulação acadêmica obtida em programas de pós-graduação stricto sensu;

III - ter todos os membros em regime de trabalho de tempo parcial ou integral, sendo pelo menos $20 \%$ em tempo integral;

IV - assegurar estratégia de renovação parcial dos integrantes do NDE de modo a assegurar continuidade no processo de acompanhamento do curso (CONAES, 2010b). 
Diante dessa normatização, na instituição objeto deste estudo, os Núcleos Docentes Estruturantes foram organizados mediante indicação e aprovação de seus integrantes pelos colegiados dos cursos de graduação, devendo ser comunicada essa decisão à Pró-Reitoria Acadêmica que, a partir de 2012, passou a expedir as respectivas Portarias de designação, motivada por solicitações feitas pelas comissões de avaliação in loco para reconhecimento de cursos.

Outra providência institucional, partindo das atribuições do NDE genericamente constantes do art. $2^{\circ}$ da Resolução n. 1 (CONAES, 2010b), foi a edição do documento Conhecendo o Núcleo Docente Estruturante (VIEIRA; GUEBERT, 2011, p. 5), no qual foram definidas as funções do NDE na instituição.

Com esse documento, nos meses de janeiro e fevereiro de 2012 foi realizada a formação de todos os integrantes de NDE da instituição, objetivando o alinhamento às orientações institucionais.

\section{O NDE como órgão colegiado na gestão educacional}

Lembrou o Parecer n. 4 (CONAES, 2010a) que, na quase totalidade dos cursos superiores, já havia um órgão colegiado que se ocupava das questões do curso, inclusive do Projeto Pedagógico do Curso, liderado pelo coordenador do curso, e que se convencionou chamar de Colegiado de Curso.

O papel exercido pelo Colegiado de Curso, no entanto, é predominantemente de caráter administrativo, resolvendo questões que envolvem aspectos relevantes do curso, mas que "normalmente se sobrepõem à necessária reflexão sobre a qualidade acadêmica do curso" (CONAES, 2010a, p. 2). Dessa forma,

[...] ainda que muitas vezes o coordenador do curso seja um professor que ajuda a dar identidade ao curso, outras tantas vezes o coordenador é um professor que exerce a importante função de fazer os fluxos não serem interrompidos, ainda que não seja um dos líderes acadêmicos no sentido colocado acima. E nisso não há demérito algum (CONAES, 2010a, p. 2). 
Ao repensar a função da Universidade e do exercício do poder em seu interior, a CONAES, instituindo o Núcleo Docente Estruturante em todos os cursos de graduação, conferiu-lhe uma natureza democrática, possibilitando a participação de um número de professores diretamente nos processos de implantação, acompanhamento e desenvolvimento dos projetos pedagógicos dos cursos. Assim, a atuação do NDE se diferencia do trabalho do colegiado do curso e do respectivo coordenador, por ter sob sua responsabilidade o processo de concepção, consolidação e contínua atualização do Projeto Pedagógico do Curso. O NDE colabora, em suma, para a construção coletiva do curso.

A participação dos professores integrantes do NDE nos cursos de graduação constitui um ato eminentemente educativo, propiciando-lhes o desenvolvimento de habilidades democráticas que cada vez mais irão torná-los competentes para participar. A participação é inerente à democracia, além de ser uma oportunidade para que o docente se mobilize, aprenda a trabalhar em equipe, elimine comportamentos individualistas e supere atitudes de acomodação.

Faz-se necessário observar, com Chauí (2000, p. 29), que:

A gestão da escola possui uma dimensão eminentemente política que precisa ser administrada, competindo aos dirigentes criar as condições para a socialização das informações, desobstruindo todos os canais de comunicação, exercendo um poder fundamentado em acordos coletivamente construídos, intersubjetivamente validados, formando-se uma grande malha de comunicação, através da prática constante da negociação, na perspectiva do agir comunicativo.

Sendo o Núcleo Docente Estruturante composto por professores que podem ser considerados a "alma do curso", por seu envolvimento e sua participação na comunidade acadêmica, uma primeira questão que vem à tona é sua característica de órgão colegiado na gestão educacional.

Para que se possa caracterizar o Núcleo Docente Estruturante do ponto de vista de sua atuação como órgão colegiado na gestão educacional, é necessário explicitar o que se entende, para os fins deste trabalho, 
por gestão educacional, expressão que se evidenciou a partir da década de 1990 e ganhou aceitação no contexto educacional.

Como explica Lück (2008, p. 53-54), a "utilização do termo gestão não corresponde a simples substituição terminológica [do termo administração], baseada em considerações semânticas". O termo envolve a "proposição de um novo entendimento de organização educacional e de seus processos e, para além disso, das relações da educação com a sociedade e das pessoas dentro do sistema de ensino e da escola". A gestão educacional não elimina a ótica da administração, mas a supera, dando-lhe uma "nova acepção, mais significativa e de caráter potencialmente transformador, colocando-a a serviço e como substrato do trabalho de gestão".

O conceito de gestão pressupõe, assim, a ideia de participação, segundo a qual todos os que fazem parte direta ou indiretamente do processo educacional estão envolvidos no estabelecimento de objetivos, na solução de problemas, na proposição de planos de ação, em sua implantação, seu acompanhamento e sua avaliação, visando aos melhores resultados do processo educacional (LÜCK et al., 2011).

A consolidação de uma gestão participativa no interior de uma instituição, no entanto, não é um processo fácil e espontâneo. Numa sociedade como a brasileira, ainda fortemente verticalizada em todos os seus aspectos, na qual as relações ocorrem entre alguém que manda (o superior) e alguém que obedece (o inferior), esse novo entendimento sobre a organização educacional e seus processos, ao se refletir na prática educativa e, consequentemente, na gestão da escola, demanda esforço coletivo permanente. Pode-se afirmar, portanto, que a tarefa de "(des) construir tanto as concepções como as práticas gestionárias das escolas passa, necessariamente, pelo desvelamento das orientações paradigmáticas que vêm informando o modelo presente nas instituições escolares, de um modo geral" (COSTA, 2005, p. 19).

$\mathrm{Na}$ concepção positivista, que respalda o modelo tradicional e aponta para a racionalidade técnico-instrumental, valorizando a padronização e a uniformidade, não há lugar para conflitos, mas também não há 
espaço para a inovação, a divergência e a diversidade. As mudanças ocorrem pela importação de ideias, processos e estratégias que deram certo em outras organizações e que são impostos de fora para dentro e de cima para baixo. A realidade, considerada estável e permanente, é previsível, isenta de crises, ambiguidades e contradições. Essa concepção, influenciada pelo modelo burocrático gerencial típico das teorias clássica e científica da administração da educação, traz "para o centro da escola as exigências de eficiência, eficácia e racionalidade, sob o comando dos imperativos capitalistas, tratando a escola à semelhança das empresas" (COSTA, 2005, p. 21).

$\mathrm{Na}$ gestão participativa, fundamentada no agir comunicativo, que sustenta a atuação do Núcleo Docente Estruturante nos cursos de graduação, a participação se soma à democracia e à cidadania, reorientando o compromisso ético-político institucional. Nela, as crises, ambiguidades e contradições são vistas como momentos de aprendizagem e de desenvolvimento, que estimulam as organizações a refletir e buscar soluções próprias para seus problemas. Há, nela, uma energia mobilizadora, que impulsiona para que os objetivos propostos sejam atingidos.

Em educação, a gestão autocrática, hierárquica e formalista do taylorismo nos remete ao passado. A revisão de seus pressupostos teóricos feita, ainda que lentamente, trouxe mudanças, e "valores contemporâneos, como flexibilidade, tolerância com as diferenças, relações mais igualitárias, justiça e cidadania" (GUTIERREZ; CATANI, 2011, p. 74), substituíram as orientações tayloristas.

Estabelecidas essas diferenças, é preciso compreender, conforme explica Costa (2005), que:

[...] a (des)construção dessas tradicionais formas de gerir a escola, assentadas nos princípios da racionalidade técnico-burocrática, reforçadora de procedimentos regulatórios e normativos, dar-se-á mediante a instauração de novas bases epistemológicas, da introdução de uma nova racionalidade, a racionalidade comunicativa (COSTA, 2005, p. 28).

A lógica da gestão, portanto, de um modo geral, 
é orientada pelos princípios democráticos e é caracterizada pelo reconhecimento da importância da participação consciente e esclarecida das pessoas nas decisões sobre a orientação, organização e planejamento de seu trabalho e articulação das várias dimensões e dos vários desdobramentos de seu processo de implementação (LÜCK, 2008, p. 36).

A gestão, em si, traz a ideia de participação e esta subentende a existência do diálogo, envolvendo o trabalho associado de pessoas orientado por uma vontade coletiva.

Na implementação e no desenvolvimento do projeto pedagógico do curso, a participação na gestão, por parte do NDE:

[...] exige a compreensão em profundidade dos problemas postos pela prática pedagógica. Ela visa romper com a separação entre concepção e execução, entre o pensar e o fazer, entre teoria e prática. Busca resgatar o controle do processo e do produto do trabalho pelos educadores (VEIGA, 1997, p. 18).

Em que consiste essa participação? Lück (2011, p. 35) identifica diferentes formas de participação: “a) a participação como presença, b) a participação como expressão verbal e discussão, c) a participação como representação política, d) a participação como tomada de decisão, e e) a participação como engajamento". Essas formas apresentam intensidades diferentes de envolvimento e compromisso, "que vão do compromisso apenas formal e distanciado ao envolvimento pleno e engajado". Nos Núcleos Docentes Estruturantes, é possível que, de acordo com a maior ou menor experiência democrática de seus integrantes, todas essas formas estejam expressas. Outros fatores, contudo, poderão interferir nessa participação, desde a pouca experiência dos professores em lidar com o confronto e a proposição de inovações, até o "autoritarismo enquanto marca do ethos educacional”, como acrescenta Silva (2005, p. 37). Esse processo participativo, no entanto, pode ser aperfeiçoado por meio da capacitação profissional e do desenvolvimento de experiências 
pedagógicas caracterizadas pela ação-reflexão-ação. É necessário que os docentes pensem sobre o que fazem, enquanto o fazem, portanto, que tenham consciência do tipo de participação que desenvolvem.

Assim, "é imprescindível conceder à gestão escolar uma feição pedagógica, [...] que deve constituir a razão de ser do ato de gerir a escola" (COSTA, 2005, p. 28). Se se deseja mudar a escola com êxito, essa mudança, que também é um processo de aprendizagem, deve vir de dentro para fora, e não de fora para dentro. Essa aprendizagem poderá ser desencadeada pela adoção do planejamento participativo, que está inserido entre as atribuições dos NDEs.

A participação dos professores integrantes dos Núcleos Docentes Estruturantes ocorre em três dimensões: política, pedagógica e técnica, de forma interdependente. Pela dimensão política, os professores participantes colaboram na construção da história pessoal e da história da instituição, buscando torná-las mais significativas; pela dimensão pedagógica, na discussão dos temas e problemas relativos ao curso de que fazem parte, colaboram com seus conhecimentos, habilidades e competências para a melhoria da qualidade do curso; pela dimensão técnica, possibilitam o alcance dos resultados almejados pelas outras duas dimensões.

Nesse contexto, ao coordenador do curso cabe criar um ambiente motivador, uma cultura participativa, para que o Núcleo Docente Estruturante possa efetivamente desenvolver seu trabalho de forma enriquecedora e competente. No que se refere à autonomia do curso, mesmo na hipótese da gestão participativa, ela é sempre relativa, uma vez que está subordinada a uma política educacional e, portanto, condicionada pelos regimentos que compõem essa política. Com efeito, as ações pedagógicas estão subjugadas ao que diz a legislação presente na política educacional.

$\mathrm{Na}$ realização desta pesquisa, foram buscadas respostas que possibilitarão uma análise da atuação do Núcleo Docente Estruturante na complexidade dos cursos a que pertencem, aliada à percepção de seus integrantes sobre seus limites e suas possibilidades em termos de gestão educacional. 


\section{Metodologia}

Do ponto de vista metodológico, a pesquisa se caracteriza como estudo de caso, portanto, de se estudar "um caso singular, situado na vida real contemporânea, bem delimitado e contextualizado em tempo e lugar para realizar uma busca circunstanciada de informações" (CHIZZOTTI, 2006, p. 136).

Neste trabalho, a percepção dos professores que integram o Núcleo Docente Estruturante dos cursos de graduação da instituição pesquisada constitui o caso estudado. "É um estudo que não visa a generalizações, mas pode revelar realidades universais, porque, guardadas as peculiaridades, nenhum caso é um fato isolado, independente das relações sociais onde ocorre" (CHIZZOTTI, 2006, p. 138).

O estudo de caso em questão é também qualitativo, caracterizado, de acordo com Merrian (1988 apud ANDRÉ, 2005, p. 17), pelos seguintes traços: particularidade, descrição, heurística e indução. Busca-se aprofundar o estudo de um fenômeno educacional singular, com o objetivo de elucidá-lo.

É relevante identificar o significado que os integrantes dos Núcleos Docentes Estruturantes da IES pesquisada atribuem à realidade da qual participam. A definição das categorias ocorreu após exaustiva leitura das respostas constantes dos questionários, até se chegar ao que Michelat (1980 apud ANDRÉ, 2006, p. 44) chamou de "impregnação" de seu conteúdo. Após leituras sucessivas, as dimensões mais evidentes vão aparecendo, as categorias vão aflorando à percepção do pesquisador.

Vale lembrar que o estudo de caso "não significa uma leitura única da realidade, supõe que pode haver diversidade de percepções" (CHIZZOTTI, 2006, p. 141).

Definidas as categorias, procedeu-se à análise e à interpretação das respostas, o que virá nos tópicos subsequentes. A partir desses resultados, foi possível ter uma visão mais profunda, ampla e integrada dos Núcleos Docentes Estruturantes e da percepção de seus integrantes. 


\section{A pesquisa de campo}

A pesquisa foi realizada em uma universidade privada, de grande porte, que possui cinco câmpus localizados no mesmo Estado, identificados como A, B, C, D e E, e aproximadamente 30 mil alunos matriculados em cursos de graduação e de pós-graduação.

Dos 486 professores integrantes de NDEs da IES, 272 responderam ao questionário: 223 integrantes do NDE de 62 cursos do câmpus A; 8 integrantes do NDE de 9 cursos do câmpus B; 21 integrantes do NDE de 10 cursos do câmpus $C$; 11 docentes de 8 cursos do câmpus D; e 9 membros de 4 cursos do câmpus E.

Considerando-se o expressivo número de professores integrantes dos Núcleos Docentes Estruturantes dos cursos que participaram da pesquisa, os resultados podem ser considerados significativos. Na menção das respostas, indicou-se o câmpus por letra maiúscula do alfabeto seguida pelo número atribuído ao questionário do participante.

Em questão que dizia respeito à percepção dos docentes sobre a exigência do Núcleo Docente Estruturante nos cursos de graduação de nível superior, analisadas as respostas, foi possível identificar duas principais categorias, categorizadas como referentes ao projeto pedagógico do curso e à gestão.

Considerando-se a categoria relacionada ao projeto pedagógico do curso, 55 respondentes (20,52\%) se manifestaram no sentido de que o NDE é de fundamental importância para o bom funcionamento do curso. Desses, 49 destacaram que essa importância se deve ao fato de possibilitar o (re)pensar do curso, com a discussão de questões político-pedagógicas relevantes, garantindo espaço de participação docente e desenvolvendo a consciência sobre o curso. Seguem algumas das respostas coletadas:

A40 - O NDE permite que pontos estratégicos e relevantes da organização didático-pedagógica do curso sejam discutidos e amadurecidos em grupo, criando um espaço democrático e colaborativo para questões como o PPC. 
A49 - É necessário para exercer o "pensar" sobre o curso, nos aspectos didático-pedagógicos, pesquisa, infraestrutura e pessoal.

D1 - O NDE é fundamental para a discussão, a análise e a reestruturação dos PPCs.

Dos professores participantes, $42(15,67 \%)$ mencionaram que o NDE permite elaborar, organizar e adequar o PPC às Diretrizes Curriculares Nacionais, ao Plano de Desenvolvimento Institucional, ao Projeto Pedagógico Institucional, às transformações do mundo e do mercado.

Quanto ao projeto pedagógico, 36 (13,43\%) dos integrantes de Núcleos Docentes Estruturantes que participaram da pesquisa destacaram que ele colabora para a excelência, a melhoria e a qualidade do curso:

A87 - É um grupo de excelência que pensa, verifica, questiona a estrutura pedagógica do curso e seu aperfeiçoamento.

A118 - É uma estratégia de enorme importância para qualificar a estruturação e gestão do curso, um espaço de reflexão e proposição sobre limites e potenciais, avaliação, revisão e (de novo) qualificação de todas as dimensões do processo pedagógico.

E5 - A importância do NDE pode ser vislumbrada principalmente no que tange à sustentação e à evolução do curso nos aspectos da consolidação e do acompanhamento paulatino do curso.

Com relação à categoria gestão do curso, os respondentes consideraram que o NDE se constitui em apoio à coordenação do curso e ao colegiado, sendo uma ferramenta importante para a gestão (24 respondentes).

Também foi mencionado que o NDE não possuía atribuições definidas na instituição: "Seu papel é fundamental para a implementação dos projetos do curso, contudo, vê-se que ainda vemos o NDE com funções bastante indefinidas" (C105).

A contribuição para a sobrecarga de atividades do professor foi citada: "Importante, mas tenho a impressão às vezes de uma sobrecarga de atividades, considerando outras funções que desempenho na universidade" (C198). 
Outra pergunta indagava sobre os limites e as possibilidades de atuação do NDE no curso, sob a ótica de seus integrantes. A maioria, nos cinco câmpus pesquisados, mencionou que os limites mais percebidos eram a falta de carga horária para o trabalho do NDE (66 professores), seguida pelas decisões emanadas dos órgãos superiores, colegiado e demais instâncias (40). Os professores referiram como limites, também, a falta de autonomia do NDE (15) e de uma rotina de trabalho, com cronograma (5).

Em menor número, os pesquisados consideraram como limites à atuação do Núcleo Docente Estruturante: a estrutura burocrática da universidade, a resistência do corpo docente a mudanças, as limitações decorrentes do próprio setor, a exigência de matrizes espelhadas e de similaridade nos planos de trabalho, o excesso de demandas quanto à elaboração dos projetos pedagógicos de cursos, os prazos enxutos definidos para essas demandas, a falta de clareza sobre as atribuições do NDE e de outros órgãos colegiados, o desconhecimento da legislação por parte dos integrantes, a dificuldade que os professores têm em trabalhar em grupo, e a falta de integração com os professores do curso.

No que diz respeito às possibilidades, houve expressiva manifestação quanto às melhorias para o curso, voltadas à elevação do nível de qualidade, por meio da discussão entre os pares (47). Foram também apontadas pelos docentes como possibilidades: a oportunidade de aprender a atuar em grupo, aproximar o curso das demandas da instituição, intermediar questões importantes, consolidar ações relativas ao PPC, propiciar maior envolvimento com os professores do curso, integrar os corpos docente e discente, dar suporte à coordenação do curso, gerir efetivamente o curso fortalecendo a relação ensino/pesquisa/extensão, trazer inovações para o curso, e unir essas possibilidades em uma única palavra - imensas.

Por último, indagou-se sobre a relação entre o Núcleo Docente Estruturante e a coordenação do curso. De modo geral, essa relação foi percebida como excelente, participativa, positiva, colaborativa, amigável, colegiada e produtiva em todos os câmpus. 


\section{Análise e interpretação dos dados}

É possível inferir, das respostas dadas às questões formuladas, que as atribuições do NDE, genericamente definidas pelo artigo $2^{\circ}$ da Resolução n. 1 (CONAES, 2010b), estão presentes entre os professores que fazem parte do Núcleo, em especial as constantes do inciso I, II e IV, que dizem respeito à qualidade do projeto pedagógico do curso, aí compreendidas a consolidação do perfil profissional do egresso, a integração curricular interdisciplinar entre as diferentes atividades do curso e o cumprimento das Diretrizes Curriculares Nacionais. O mesmo não se pode dizer do contido no inciso III, que se refere a "formas de incentivo ao desenvolvimento de linhas de pesquisa e extensão, oriundas de necessidades da graduação, de exigências do mercado de trabalho e afinadas com as políticas públicas relativas à área de conhecimento do curso", não mencionado pelos pesquisados.

A percepção da importância do Núcleo Docente Estruturante como indutor da excelência do projeto pedagógico do curso ficou evidenciada de forma incontestável. O fato de poucos docentes se preocuparem em destacar a vivência em um processo de gestão democrática pode suscitar algumas reflexões. Uma primeira hipótese seria de que, como numa instituição privada de educação superior eles constituem exceção, os docentes não a tenham percebido em sua plenitude. Com efeito, para alguns deles, o NDE surge como "uma obrigação imposta pelo MEC", portanto eles não percebem o início de um processo de democratização. Outra hipótese seria de que a participação docente não tenha atingido ainda as fases identificadas por Lück (2011) como de tomada de decisão e engajamento, sendo exercitadas ainda com presença, expressão verbal e discussão - etapas iniciais do processo participativo. Nessa hipótese, a criação de um ambiente participativo, do qual os professores façam parte, conscientes da relevância de sua função, deverá ser construída e conquistada.

Pode-se argumentar que a relativa falta de autonomia dos NDEs faz parte de sua natureza, uma vez que o processo de elaboração, acompanhamento e avaliação dos projetos pedagógicos dos cursos deve ser 
monitorado e avaliado pelo colegiado e, em última instância, por toda a comunidade escolar. Nesse monitoramento, estão o cumprimento das decisões emanadas dos órgãos superiores da instituição, e a observância das Diretrizes Curriculares Nacionais e de todo o aparato legislativo que orienta a educação superior no país.

Quanto às possibilidades percebidas, as referências dos integrantes dos NDEs permitem-nos interpretá-las em uma visão otimista, em termos de que efetivamente podem colaborar com as melhorias do curso, seja por meio de discussões em grupo sobre temas pedagógicos relevantes, de encontros para reflexão, no desempenho de um papel estratégico nos moldes de um think-talk para o curso, no diálogo constante com os pares para o realinhamento das ações no curso, entre outras ações.

As relações dos Núcleos Docentes Estruturantes com as respectivas coordenações de curso parecem ser auspiciosas. Os participantes citaram uma relação de proximidade, sintonia, integração, cordialidade, incentivadora, integrada, enfim, com vocábulos que denotam uma convivência fácil e proveitosa, com sinergia, parceira, voltada à melhoria do curso.

\section{Considerações finais}

O NDE, integrante das políticas públicas educacionais, está em seus primeiros anos de implantação e pode se tornar instrumento de gestão democrática que garanta a melhoria da qualidade da educação. Sua simples instituição, porém, não promoverá a democratização do processo de gestão. Por isso, esta pesquisa visou, além de resumir os fundamentos políticos e as normas que estabeleceram a obrigatoriedade do NDE em todos os cursos de graduação, investigar a percepção dos integrantes do NDE dos cursos pesquisados a respeito da exigência dessa implantação, dos limites e das possibilidades em sua atuação e da relação com a coordenação do curso, a fim de promover a melhoria da qualidade da educação superior ofertada.

Os dados coletados evidenciaram a importância de existir um Núcleo Docente Estruturante para pensar o curso, tendo sido apontadas 
diversas vantagens em relação a essa participação. É relevante que o NDE esteja composto de acordo com as determinações da CONAES, tanto em número de integrantes quanto no que se refere à carga horária e à titulação dos professores, o que não ocorria na instituição pesquisada até o momento da coleta de informações.

Com efeito, o NDE não é um setor burocrático da instituição, mas um órgão colegiado, regulamentado, constante do estatuto ou do regimento da instituição, com funções definidas pela CONAES. Observe-se que a ênfase na participação dos docentes na gestão escolar é uma tendência mundial para a educação. No entanto, não há modelos predeterminados de participação. Assim, enquanto em alguns cursos essa atuação está mais estruturada e definida, em outros, é apenas incipiente. Cada curso tem a incumbência de construir seu próprio caminho, de acordo com as visões de homem, de mundo, de sociedade e de história que conduzem as ações humanas. Esse caminho oscilará entre a opção pelos princípios democráticos ou pelas estratégias técnico-científicas. O grupo de professores que compõem o NDE deve estar efetiva e continuamente comprometido com a elaboração, o desenvolvimento e a consolidação do projeto pedagógico do curso ao qual pertence.

A autonomia não significa independência. Ela precisa ser cotidianamente construída, passo a passo, para a construção e a garantia da efetivação dos processos democráticos.

Por ser um órgão relativamente novo na estrutura do curso, pairam algumas dúvidas e expectativas sobre sua atuação. Para muitos docentes, ainda falta clareza sobre o trabalho a ser desenvolvido. Outros desejariam que, além do que dispõe a Resolução n. 1 (CONAES, 2010b), também a instituição estabelecesse limites de atuação. A atuação no NDE deverá, paulatinamente, colaborar para esclarecer essas dúvidas.

Dos dados coletados, foi possível perceber que as grandes áreas de interferência do NDE são a parte pedagógica e a gestão do curso. Com todos os limites que a realidade, em sua complexidade, impõe, o NDE vem possibilitando o envolvimento dos professores no desenvolvimento do projeto pedagógico e na gestão do curso. 
Do ponto de vista pedagógico, a contribuição mais significativa é a possibilidade de analisar, discutir, colaborando para a melhoria da qualidade do curso. Quanto à gestão do curso, a atuação como órgão consultivo da coordenação e do colegiado está definida, conquanto alguns discutam se as funções eventualmente exercidas não extrapolariam para a faixa de execução de atividades.

A indagação sobre os limites e as possibilidades de atuação do NDE no curso traz a preocupação com a necessidade de atendimento às normas do MEC e da instituição, o que interferiria na autonomia do órgão. As possibilidades, por outro lado, apontam para um trabalho de estímulo à interdisciplinaridade, à atualização do projeto pedagógico do curso e à contínua melhoria do perfil do egresso. Nesse particular, recomenda-se cuidado para que o NDE não se torne apenas um espaço burocrático, esvaziado de sua função política; ele deve ser uma instância de análises e discussões voltadas à melhoria da qualidade da educação superior ofertada.

$\mathrm{Na}$ instituição pesquisada, a relação com a coordenação do curso é bastante próxima, possibilitando a participação e a decisão coletiva, em uma aprendizagem que está sendo realizada pelos NDEs pesquisados. Contudo, se, por um lado, a participação do coordenador no NDE permite melhor relacionamento, por outro, ela pode inibir discussões que não estejam alinhadas à visão da coordenação, interferindo, indiretamente, no processo de melhoria do curso.

É certo que o coordenador, como líder do processo de gestão democrática, encontra no NDE competências que o ajudam a conduzir o curso, em consonância com as diretrizes institucionais. Com a participação do NDE, o gestor não se sentirá sozinho em sua tarefa de condução do curso. A criação de condições que melhor efetivem essa participação, no entanto, está sob sua responsabilidade. É preciso tentar encontrar um caminho de (des)construção da gestão como ela vem sendo realizada, para que o NDE se torne mais participante nas decisões, aumentando os espaços de exercício do poder. A modernização das práticas pedagógicas inspiradas no modelo positivista não é suficiente para que sejam abertos espaços para participação, problematização, análise crítica da realidade 
social e geração de práticas inovadoras. Acrescente-se que o NDE não visa retirar o poder do coordenador, mas redefini-lo.

Citando Gutierrez e Catani (2011, p. 91), a busca da construção comunicativa do consenso pelo diálogo deve ser realizada com "todos os envolvidos, e não apenas com aqueles que pensam como nós”.

Por último, vale mencionar que os dados coletados contêm uma riqueza de informações que ultrapassa os limites deste trabalho. Assim, a continuidade da análise das manifestações dos docentes possibilitará aprofundar questões como a definição do caráter consultivo do NDE, dos conceitos subjacentes às ideias expostas, da mais adequada forma de atuação frente aos limites identificados e de outros tópicos que estimularão novas pesquisas sobre o tema.

\section{Referências}

ANDRÉ, M. E. D. A. de. Estudo de caso em pesquisa e avaliação educacional. Brasília: Líber Livro, 2005. (Série Pesquisa, v. 13).

ANDRÉ, M. E. D. A. de. A pesquisa no cotidiano escolar. In: FAZENDA, I. (Org.). Metodologia da pesquisa educacional. São Paulo: Cortez, 2006. p. 35-45.

BOGDAN, R.; BIKLEN, S. K. Investigação qualitativa em educação: uma introdução à teoria e aos métodos. Porto: Porto Editora, 1994.

BRASIL. Constituição (1988). Constituição: República Federativa do Brasil. Brasília, DF: Senado Federal, 1988.

BRASIL. Lei n. 9.394, de 20 de dezembro de 1996. Diário Oficial [da] República Federativa do Brasil, Brasília, DF, 23 dez. 1996. Disponível em: <http://www.planalto.gov.br/ccivil_03/leis/19394.htm>. Acesso em: 10 maio 2013. 
BRASIL. Lei n. 10.861, de 14 de abril de 2004. Institui o Sistema Nacional de Avaliação da Educação Superior - SINAES e dá outras providências. Diário Oficial [da] República Federativa do Brasil, Brasília, 15 abr. 2004. Disponível em: <http://www.planalto.gov. br/ccivil_03/_ato2004-2006/2004/lei/110.861.htm>. Acesso em: 10 maio 2013.

BRASIL. Ministério da Educação. Portaria n. 147, de 2 de fevereiro de 2007. Dispõe sobre a complementação da instrução dos pedidos de autorização de cursos de graduação em direito e medicina, para os fins do disposto no art. 31 , $\S 1^{\circ}$, do Decreto n. 5.773, de 9 de maio de 2006. Diário Oficial [da] República Federativa do Brasil. Brasília, 2 fev. 2007. Disponível em: <http://www.unimep.br/cavi/documents/12_portaria_mec_147.pdf>. Acesso em : 10 maio 2013.

BRASIL. Ministério da Educação. Portaria Normativa n. 40, de 12 de dezembro de 2007. Institui o e-MEC, sistema eletrônico de fluxo de trabalho e gerenciamento de informações relativas aos processos de regulação da educação superior no sistema federal de educação. Diário Oficial [da] República Federativa do Brasil, Brasília, 29 dez. 2010. Disponível em: <http://download.inep.gov.br/download// superior/2011/portaria_normativa_n40_12_dezembro_2007.pdf >. Acesso em: 10 maio 2013.

BRASIL. Ministério da Educação. Portaria n. 1.081, de 29 de agosto de 2008. Aprova, em extrato, o Instrumento de Avaliação de Cursos de Graduação do Sistema Nacional de Avaliação da Educação Superior - SINAES. Diário Oficial [da] República Federativa do Brasil, Brasília, 29 ago. 2008. Disponível em: <http:// download.inep.gov.br/download/superior/condicoesdeensino/Portaria_1081_ de_29_08_2008\%20_Instrumento_de_renov_rec.pdf >. Acesso em: 10 maio 2013. CHAUÍ, M. Brasil: mito fundador e sociedade autoritária. São Paulo: Fundação Perseu Abramo, 2000.

CHIZZOTTI, A. Pesquisa qualitativa em ciências humanas e sociais. Petrópolis: Vozes, 2006. 
COMISSÃO NACIONAL DE AVALIAÇÃO DA EDUCAÇÃO SUPERIOR CONAES. Parecer n. 4, de 17 de junho de 2010a. Dispõe sobre o Núcleo Docente Estruturante - NDE. Disponível em: <http://portal.mec.gov.br/index. php?option=com_content\&view=article\&id=15712\&Itemid=1093 $>$. Acesso em: 10 maio 2013.

COMISSÃO NACIONAL DE AVALIAÇÃO DA EDUCAÇÃO SUPERIOR CONAES. Resolução n. 1, de 17 de junho de 2010b. Normatiza o Núcleo Docente Estruturante e dá outras providências. Disponível em: <http://portal.mec.gov. br/index.php?option=com_content\&view=article\&id=15712\&Itemid=1093 > . Acesso em: 10 maio 2013.

COSTA, C. M. É possível des-construir e re-construir a concepção e a prática vigentes da gestão escolar? Da visão tecnocrático-regulatória à visão comunicativo-emancipatória. Revista de Educação AEC, ano 34, p. 18-31, abr./jun. 2005.

GUTIERREZ, G. L.; CATANI, A. M. Participação e gestão escolar: conceitos e potencialidades. In: FERREIRA, N. S. C. (Org.). Gestão democrática da educação: atuais tendências, novos desafios. São Paulo: Cortez, 2011. p. 73-92.

LÜCK, H. Gestão educacional: uma questão paradigmática. Petrópolis: Vozes, 2008.

LÜCK, H. A gestão participativa na escola. Petrópolis: Vozes, 2011.

LÜCK, H. et al. A escola participativa: o trabalho do gestor escolar. Petrópolis: Vozes, 2011.

PEREIRA, D. Função social da educação jurídica. Direito e Sociedade - Revista de Estudos Jurídicos e Interdisciplinares, Catanduva, v. 6, n. 1, p. 32-45, jan./dez. 2011.

SANTOS, A. L. F. dos. Gestão democrática da escola: bases epistemológicas, políticas e pedagógicas. In: GOMES, A. M. (Org.). Políticas públicas e gestão da educação. Campinas: Mercado das Letras, 2011. p. 35-55.

SILVA, I. É possível desconstruir e reconstruir a concepção e a prática vigentes da participação na escola? Revista da Educação AEC, ano 34, p. 32-40, abr./jun. 2005. 
VEIGA, I. P. A. (Org.). Projeto político-pedagógico da escola: uma construção possível. Campinas: Papirus, 1997.

VIEIRA, A. M. D. P.; GUEBERT, M. C. C. Conhecendo o Núcleo Docente Estruturante. Curitiba: PUCPR - Pró-Reitoria Acadêmica, 2011.

Recebido: 20/11/2014

Received: 11/20/2014

Aprovado: 16/12/2014 Approved: 12/16/2014 
